\title{
O papel social da biblioteca pública na interação entre informação e conhecimento no contexto da ciência da informação
}

Maria Cleide Rodrigues Bernardino

\begin{abstract}
Professora Assistente do Curso de Biblioteconomia da Universidade Federal do Ceará - UFC/Campus Cariri. Doutoranda em Ciência da Informação pela Universidade de Brasília - UnB Bolsista Capes.
\end{abstract}

Emir Jose Suaiden

\begin{abstract}
Professor Titular da Faculdade de Ciência da Informação da Universidade de Brasília - UnB. Diretor do Ibict.
\end{abstract}

Destaca a importância da biblioteca pública para a sociedade e a relevância de seu papel social. Traz a observação da relação de interação entre informação e conhecimento processada na mente dos usuários, sob os auspícios da Ciência da Informação. O lugar da biblioteca pública na sociedade, seu papel fomentador da leitura e da cultura e a relação intrínseca com a comunidade, gerando conhecimento e favorecendo a cidadania são aspectos apontados, respaldados pelos ditames do Manifesto da UNESCO, que traz a biblioteca pública como porta de entrada para o conhecimento. Por fim, propõe a reflexão e o desenvolvimento de projetos culturais de incentivo à leitura, como condições favoráveis para a criação de relações entre a comunidade usuária, proporcionando à biblioteca pública, condições apropriadas para firmar seu papel, enquanto fomentadora da cultura na sociedade.

Palavras-chave: Biblioteca Pública; Ciência da Informação; Informação - Conhecimento. 


\title{
The role of social interaction between public library in information and knowledge in the context of information science
}

\begin{abstract}
Stresses the importance of the public library for the society and the relevance of their social role. Bring the observation of the relationship of interaction between information and knowledge processed at the user's mind, under the auspices of Information Science. The place of the public library in society, its enhancing role of reading and culture and close relationship with the community, generating knowledge and promoting citizenship are criticisms, backed by the dictates of the UNESCO Manifest, which brings the public library as a gateway for knowledge. Finally, it proposes a reflection and development of cultural projects to promote reading as favorable conditions for the establishment of relations between the user community, providing the public library, under appropriate conditions to secure its role as a stimulator of culture in society.
\end{abstract}

Keywords: Public Library; Information Science; Social Role - Reading.

Recebido em 30.03.2011 aceito em 12.12.2011

\section{Introdução}

A história da leitura acompanhou efetivamente a evolução da história das bibliotecas e passeando rapidamente por esta trajetória histórica, constatamos que, com a expansão da educação, as bibliotecas públicas, que eram consideradas como um instrumento de apoio pedagógico, são assimiladas pelas classes populares e pela escola, transformando-se no que alguns teóricos chamam de biblioteca escolarizante (MILANESI, 2002). Entretanto, as bibliotecas públicas, até este momento, eram mantidas e manipuladas por nobres, instituições religiosas e educacionais.

A problemática acerca do livro e da leitura no Brasil não é uma discussão nova. Ao contrário, é alvo recorrente de pesquisas, projetos e principalmente de críticas. Pensar a leitura como uma ação efetiva da biblioteca é necessário. Pensar como uma ação específica da Biblioteca Pública é uma ordem. 
O papel social da Biblioteca Pública é permeado pelo acesso e disponibilidade da informação. A relação entre estsa informação e o conhecimento é observada sob a ótica da Ciência da Informação a partir de 1980 (BARRETO, 2007, p. 25), e foi introduzida por Belkin, Wersig e Vevelling, através dos trabalhos: Project in Scientific Information Exchange in Psycology, da American Psycological Association; do Center for Reseach in Scientific Comunication da John Hopkin University e o INFROSS Project na Universidade de Bath.

A partir de então, conseguimos verificar na historiografia da Ciência da Informação a interação entre a informação e o conhecimento, ou seja, a informação para gerar conhecimento. Essa discussão é mediada pelo caráter interdisciplinar da ciência da informação, que permite um recorte com áreas como a filosofia, ciência cognitiva, sociologia, linguística e outras (SARACEVIC, 1995).

Quando dizemos que o papel social da biblioteca pública está no acesso e disponibilidade à informação, traçamos claramente um objetivo crucial dessas instituições, ele poderá ser alcançado através de projetos culturais que visem à disseminação da leitura.

Um dos serviços da Biblioteca Pública perante a sua comunidade é a introdução de projetos culturais, atendendo ao seu objetivo de disseminar a cultura e a leitura aos seus usuários. A realização de projetos culturais de leitura em bibliotecas já faz parte do leque de atividades destas e coincidem quanto ao objetivo principal, que é incentivar a leitura e a cultura na comunidade.

\section{Interação entre informação e conhecimento}

Barreto (2007, p. 27) afirma que o conhecimento é organizado em estruturas mentais, por meio das quais um sujeito assimila a informação. Ao focalizar a investigação na relação entre a informação e o conhecimento, a apreciação da informação passa à coletividade. $O$ ato de conhecer pode, ao mesmo tempo, ser um ato de interpretação individual e coletiva.

Podemos nos basear na afirmação de que

A geração de conhecimento é uma reconstrução das estruturas mentais do indivíduo realizado através de sua competência cognitiva, ou seja, é uma modificação em seu estoque mental de saber acumulado, resultante de uma interação com uma forma de informação (BARRETO, 2007, p. 27).

Ao afirmarmos, baseando-nos em Barreto (2007), que a geração do conhecimento se dá através de uma interação com a informação, também afirmamos que é responsabilidade da Ciência da Informação estudar essas relações por se tratar do fluxo informacional e respaldando-nos do que diz Borko (1968), ao conceituar a Ciência da Informação como a disciplina que "investiga as propriedades e o comportamento da informação, as 
forças que regem o fluxo informacional e os meios de processamento da informação para otimização do acesso e uso". E, ainda, no que nos diz Amaral (2008, p. 58), ao falar que: "a informação, como insumo para o conhecimento deveria ser defendida como objeto de estudo da área".

Neste sentido, podemos afirmar, baseando-nos no Manifesto da UNESCO para Bibliotecas Públicas, que é um direito da comunidade o acesso à informação e à apropriação do conhecimento. E, mais ainda, a biblioteca pública, como diz o manifesto, é a "porta de entrada para o conhecimento", e são missões desta "a informação, alfabetização, educação e cultura, devendo estar impressas na essência dos serviços da biblioteca pública" (MACEDO; SEMEGHINI-SIQUEIRA, 2000, p. 23).

Portanto, entendemos que há uma relação entre o que diz a missão da biblioteca pública: oferecer serviços com base na disseminação da informação, cultura e do conhecimento e o que diz a ciência da informação ao estudar a relação entre a informação e o conhecimento, ou a informação geradora de conhecimento.

A biblioteca pública se caracteriza como um local de construção permanente de cultura, uma vez que permite a aprendizagem permanente, conforme o Manifesto: "A biblioteca pública, porta de entrada para o conhecimento, proporciona condições básicas para a aprendizagem permanente, autonomia de decisão e desenvolvimento cultural dos indivíduos e grupos sociais" (MANIFESTO DA UNESCO, 1994).

A leitura tem um papel preponderante nesse contexto, uma vez que para a consolidação de uma sociedade da informação e do conhecimento, a democratização da leitura é fundamental. Questões como essas devem ser pensadas pela Ciência da Informação dentro do contexto de responsabilidade social, aplicando às práticas leitoras condições que possibilitem a construção do conhecimento.

Afirmamos que a relevância do tema "interação entre informação e conhecimento", para a Ciência da Informação, se manifesta quando os objetivos dessa área permanecem imbricados às práticas sociais de leitura, que dão suporte informacional para a construção de uma sociedade contemporânea que seja capaz não apenas de discutir a problemática que afeta o acesso à leitura e à informação, mas implantar e fortalecer políticas de governo que venham a minimizá-la e estabelecer conexões facilitadoras em busca de uma sociedade do conhecimento.

Lembrando que o acesso à informação é um direito. Esse direito é defendido e garantido pelo Manifesto da UNESCO, que diz que: "os serviços fornecidos pela biblioteca pública baseiam-se na igualdade de acesso para todos, independente de idade, raça, sexo, religião, nacionalidade, língua ou status social" (MACEDO; SEMEGHINI-SIQUEIRA, 2000, p. 51).

A biblioteca como lugar de interação entre a leitura e o leitor, conservação e preservação da memória, mas, sobretudo, uma interseção entre esta e seus leitores e principalmente para estes, sejam dedicados todos os seus esforços, tanto no que diz respeito à organização e tratamento da informação como à disseminação da cultura. Uma 
biblioteca que atue como centro fomentador e gerador do conhecimento, como o próprio manifesto diz: porta aberta para o conhecimento.

E, como assumir essas funções em meio ao emaranhado de problemas acumulados ao longo da história? Como acompanhar as tecnologias em meio às desigualdades sociais? Em primeiro lugar, é preciso deixar de ter funções colocadas sabiamente em retórica poética, mas assumir sua função transformadora da sociedade e caminhar junto com sua clientela, de forma a construir o conhecimento. É preciso pensar no usuário. É preciso, sobretudo, pensar na responsabilidade social da biblioteca pública e em sua função intermediadora entre o leitor e a informação, e consequentemente, o conhecimento.

Acreditamos que, assim, a biblioteca deixará aquela imagem, muitas vezes associada à punição e passará a ser um espaço democrático de fomento ao saber. Podendo, então, inscrever um novo perfil na história, mais moderno e condizente com os anseios da comunidade usuária, ou seja, que suas intervenções sejam voltadas para as necessidades dos usuários.

\section{Biblioteca pública como lugar de leitura e apropriação de conhecimento}

Historicamente, no que diz respeito às bibliotecas públicas, foi na década de 1970 que surgiu a preocupação com os usuários, com pesquisas e estudos voltados para eles, como estudo de usuários. Porém, foi na década de 1980 que a Biblioteconomia preocupou-se com a circulação da informação. Entretanto, o caminho ainda é longo. Repensar a biblioteca pública e seu papel na Sociedade da Informação, ainda é um projeto.

[...] os diversos segmentos da sociedade têm expectativas diferentes em relação ao papel da biblioteca pública. A indústria editorial acredita que o objetivo fundamental é a formação de um público leitor. Os educadores acreditam que a biblioteca deve ser 0 alicerce do processo ensinoaprendizagem. Os intelectuais acreditam que deve ser um espaço rico em literatura de ficção. $O$ trabalhador comum não vê a biblioteca como um local para solucionar os problemas do cotidiano (SUAIDEN, 2000, p. 57).

E, como mudar esse quadro, uma vez que a Biblioteca Pública é um espaço para o educador, o intelectual, o trabalhador e todos que dela venham a precisar? Até mesmo pela própria força de seu nome que carrega um adjetivo que a torna comum a todos e que acaba por pressupor um atendimento geral, sem distinção alguma.

Martins (2002, p. 325) nos diz que:

[...] o adjetivo pública, que contemporaneamente se juntou ao nome da biblioteca, não corresponde apenas ao desejo de 
identificá-la como organismo mantido pelo governo ou por entidades particulares, mas aberto a todos os interessados.

Dessa forma, ainda segundo Martins (2002, p. 326), a palavra pública deve ser encarada em seu sentido mais profundo e em toda a extensão do seu significado. A Biblioteca Pública, em seu verdadeiro sentido de atuação, livre, aberta, democrática, socializadora, que ao mesmo tempo em que cuida da preservação da memória investe na construção do conhecimento e soma esforços para que transforme e seja transformada para e pelo usuário, e que, em razão deste, possa se tornar um ambiente vivo e efervescente de cultura.

O reconhecimento do caráter público e comum a todos como identidade da biblioteca pública fortalecem, ainda, o entendimento de que "o estreitamento da relação com a comunidade é fator essencial para o desempenho das funções da biblioteca pública", ampliando as "possibilidades de acesso à informação e de geração e transmissão de conhecimento" (BIBLIOTECA PÚBLICA, 2010, p. 103). Este reconhecimento facilitará a atuação da biblioteca pública na sociedade e garantirá, a partir da compreensão e assimilação desta, um lugar de interação entre informação e conhecimento, por parte dos indivíduos de uma comunidade.

Miranda (1978, p. 69) nos questiona sobre a missão da biblioteca pública em um país de dimensões continentais e desnivelamentos regionais marcantes, e nos responde dizendo:

Não pretendemos dar uma resposta definitiva - mesmo porque a biblioteca é um fenômeno histórico em regime de mútua e permanente influência (interação) com 0 meioambiente e também porque toda instituição (apesar dos tecnocratas e dos apologistas da "administração por objetivos") está umbilicalmente ligada àqueles que a organizam, que a fazem viver, que emprestam a ela a marca de sua vontade e de sua personalidade. A biblioteca é, por conseguinte, uma célula viva, única. Nenhuma biblioteca é igual a outra. Consequentemente, objetivos gerais acabam por ajustarem-se às possibilidades e necessidades específicas de cada biblioteca. Longe de constituir-se numa desvantagem, esta é a essência mesma de qualquer instituição democrática: a de ajustar-se a um plano diretor ou a um sistema geral sem perder de vista os seus próprios objetivos, sem renunciar a satisfazer as necessidades peculiares de seus próprios usuários.

Quando Antonio de Miranda diz que a biblioteca é uma célula viva, nenhuma é igual a outra, isto não se constitui em uma desvantagem. Isso é uma imagem muito forte do que a biblioteca representa para a comunidade a qual está inserida, um organismo que converge seus objetivos em favor do usuário, para suas necessidades e particularidades 
de informação. Chama a atenção, também, para o fato de que a sociedade e, consequentemente, os indivíduos de uma sociedade, não são imutáveis, pelo contrário, vivem em constante evolução e interação com a comunidade.

A chamada sociedade da informação em um país com as disparidades culturais como o Brasil é uma árdua tarefa, que requer, acima de tudo, vontade política, de forma a viabilizar as ações da Biblioteca Pública voltadas para a sua comunidade e suas diferenças. Exige um projeto de ação agressivo e regional, tendo em vista as particularidades de cada região brasileira, mas, sobretudo, exige uma consciência geral de que é preciso acompanhar as mudanças da sociedade e que a biblioteca é parte integrante dessa evolução.

É inegável o envolvimento da leitura para o fortalecimento e efetivação da missão da biblioteca pública. Os projetos culturais de leitura desenvolvidos por estas Unidades de Informação preveem a aquisição da cultura e do conhecimento, através de um delineamento de um leque de ações com metas bem definidas.

Enfatizamos, outrossim, a polissemia da noção de leitura, distinguindo as suas múltiplas concepções. A leitura é uma questão de natureza, de condições, de modos de real ação, de trabalho, de produção de sentidos, de historicidade (ORLANDI, 1999).

Baseamo-nos no que diz Martins (1982, p. 30): "a leitura deve ser considerada como um processo de compreensão de expressões formais e simbólicas, não importando por meio de que linguagem". Dessa forma, a concepção de texto se amplia e não fica limitada ao que está escrito, passa a reunir diferentes tipos de linguagens. Sendo assim, a autora afirma que: "ler significa também aprender a ler o mundo, dar sentido a ele e a nós próprios".

\section{0 papel social da ciência da informação e da biblioteca público}

Entendemos por Ciência da Informação, a ciência que estuda a informação desde a sua gênese até o processo de transformação de dados em conhecimento. Além de estudar a aplicação da informação nas organizações, estuda, também, as interações entre as pessoas e os sistemas de informação, a própria logística da Informação, seu planejamento, modelagem de dados e análise, etc.

A maioria dos teóricos procura explicitar a origem e a fundamentação da Ciência da Informação e nesta tentativa seus discursos se configuram como um escopo de ideologia, que abriga os mais variados discursos contextualizados em um lugar social específico. Almeida (2007, p.72) diz que:

A ciência da informação é um campo social de produção do conhecimento voltado às questões ligadas à informação. A história deste campo não pode ser relatada simplesmente pela 
menção de datas ou fatos, pois assim se esquece das demandas sociais que a determinaram e legitimam sua existência ainda hoje. (grifo nosso).

O conceito da Ciência da Informação está, assim, atrelado a sua demanda social e a sua existência condicionada ao seu uso e necessidade. Ao afirmar que a Ciência da Informação é um campo social, o autor delimita sua área de atuação e, mais à frente, ao afirmar que sua história não pode ser relatada apenas cronologicamente e sim, também pelas suas demandas sociais, que em sua fala, "a determinaram e legitimam". Este discurso constrói ideologicamente que a ciência da informação tem sua existência determinada pelas demandas sociais.

Afirmações como essa e como a de Borko (1968), que definem a Ciência da Informação como uma "disciplina que investiga as propriedades e o comportamento da informação, as forças que regem o fluxo informacional e os meios de processamento da informação para a otimização do acesso e do uso", (grifo nosso), fortalecem o conceito de informação para o uso, associando o entendimento da ciência da informação às suas necessidades sociais.

A Ciência da Informação participa ativamente do fenômeno que transforma a informação em conhecimento e a Biblioteca Pública, enquanto instituição que abriga em seu escopo a máxima de acesso à informação a todos sem distinção é o lugar social desse fenômeno. Essa dinâmica é fator fundamental na sociedade atual, que associa informação a poder de forma tão clara e objetiva. Neste sentido, "[...] cabe à biblioteca pública atuar, como instituição democrática por excelência [...]" uma vez que "[...] agrupa e proporciona o acesso aos registros do conhecimento e das ideias do ser humano através de suas expressões criadoras". (BIBLIOTECA PÚBLICA, 2010, p. 17).

A Ciência da Informação, juntamente com a Biblioteconomia, compartilha do mesmo papel social, que por sua vez está amparado no uso eficaz dos registros, no acesso e no uso da informação e, claro, na importância do contexto social, dos sujeitos, que ao mesmo tempo em que produzem informação, também a buscam e a usam. Neste sentido, a aplicabilidade da informação para a sociedade, conhecida como Sociedade da Informação, contribui para um pensamento que conduz para o reconhecimento da responsabilidade social de ambas as áreas.

Barreto (2007, p. 27) diz que o foco na relação da informação e do conhecimento acabou modificando a própria importância da gestão dos estoques de informação, dando um sentido mais coletivo ao seu uso. Assim, o papel social da Biblioteca Pública congrega os mesmos valores da Biblioteconomia e da Ciência da Informação, uma vez que está galgado no acesso democrático da informação. Entretanto, faz-se necessário que as Bibliotecas Públicas se modernizem e melhorem seu aparato tecnológico, em consonância com as exigências da sociedade da informação.

Em uma sociedade que vive hoje a era do conhecimento é inegável a intrínseca relação da Ciência da Informação com as tecnologias, como esclarece Barreto (2007, p. 14): "[...] a área de ciência da informação se 
reconstrói ao sabor das inovações na tecnologia". E, diríamos, que é simplesmente inegável a consequente relação da Biblioteca Pública e as tecnologias, por ser uma demanda social e por fazer parte de maneira vicária da natureza social da Biblitoeca Pública, participando, assim, ativamente da interação entre a informação e o conhecimento em um fenômeno capaz de alavancar todas as esferas da sociedade, dentro de um contexto abrangente de cultura.

Para tanto, a atuação das Biblitecas Públicas como produtoras de conhecimento é mediada pelas intervenções na sociedade, permeadas pelos projetos culturais de leitura, a fim de atuar concretamente na comunidade usuária, construindo laços sociais que garantem o fenômeno da transformação da informação em conhecimento.

\section{Projetos culturais e de leitura nas bibliotecas públicas}

Ao nos basearmos nas concepções de leitura, somos induzidos a refletir sobre elas, teoricamente extraindo-lhe alguns significados, tais como: leitura de mundo (FREIRE, 1991); prática social (SOARES, 1999); e atribuição de sentidos (ORLANDI, 1999); (MARTINS, 1982). Leitura como apropriação da informação (ALMEIDA JÚNIOR, 2007). As concepções convergem para nossa afirmação, enquanto leitura como apropriação de conhecimento. Sendo assim, podemos afirmar que ao introduzir na comunidade usuária ações com o intuito de possibilitar a inserção desta às práticas leitoras, dizemos, também, que a biblioteca proporciona oportunidades de geração de conhecimento, uma vez que este se dá pelo processo da leitura.

Assim, projetos de leitura desenvolvidos por bibliotecas públicas oportunizam a comunidade usuária o desenvolvimento social e cultural, uma vez que proporcionam o adentramento ao mundo letrado e não letrado da leitura, criando, assim, condições de geração de conhecimento, tendo como pressuposto teórico a concepção interacionista e sócio construtivista de Bahktin (1984) e Vygostski (1987), que permitem uma ampliação do entendimento da leitura e sua prática.

Neste sentido, a informação que é processada através da leitura, somada ao aspecto significativo da representatividade das bibliotecas perante a comunidade, a fim de construir conhecimento e disseminar a cultura, torna-se um organismo único e indissociável. $E$, ainda, tomamos como base o pressuposto da missão da biblioteca pública apontada através do Manifesto da UNESCO, que a coloca como centro de construção do conhecimento, estabelecendo links com a educação e a cultura, essa relação se fortalece e permite a interação entre informação e conhecimento.

Neste aspecto, o papel do leitor é fundamental, uma vez que "o lugar onde a informação se faz conhecimento é na consciência do receptor que precisa ter condições para aceitar a informação e a interiorizar" (BARRETO, 2007, p. 24). 

pública é:

Pautadas pelo Manifesto da UNESCO, que prevê que a biblioteca

[...] local de informação, tornando prontamente acessíveis aos seus utilizadores o conhecimento e a informação de todos os gêneros [...] Todos os grupos etários devem encontrar documentos adequados às suas necessidades. As coleções e serviços devem incluir todos os tipos de suporte e tecnologias modernas apropriados, assim como materiais tradicionais (IFLA/UNESCO, 1994).

As bibliotecas públicas precisam, para cumprir o que prevê o Manifesto, oferecer serviços com base na igualdade de acesso para todos, sem distinção, disponibilizar serviços e materiais específicos, dispor ainda de documentos adequados às necessidades de todos. Precisa, sobretudo, compreender seu valor e missão perante a sociedade, funcionando como um espaço sociocultural, que dispõe de produtos e serviços informacionais para a comunidade em geral e possuir em seu acervo uma ampla gama de assuntos em múltiplos suportes.

Ao assumir seu papel perante sua comunidade, a biblioteca pública reconhecerá sua função social e incorporará, além do seu objetivo primordial, que é preservar e difundir o conhecimento, fazendo isto, principalmente no que se refere à cultura local, mas, incorporará, também, a própria comunidade do seu entorno, as suas funções e atribuições, sendo reconhecida e legitimada pela sociedade, uma vez que a biblioteca pública (SUAIDEN, 1995, p.20), dentre todos os tipos de bibliotecas, é a única que possui realmente características de uma instituição social, tanto pela amplitude de seu campo de ação quanto pela diversificação de seus usuários.

Essas novas exigências da biblioteca pública pressupõem um profissional com competências e habilidades compatíveis, conhecimento geral e participação política. Compor o acervo da biblioteca pública, gerir esses documentos e as ações, como projetos de leitura, é papel do bibliotecário gestor. Assim, como afirmam Rache e Varvakis (2006, p.137):

Percebe-se que os serviços é que vão conferir à biblioteca sua dinâmica, sua capacidade de transpor a métrica e estabilidade de seus acervos, permitindo a concretização da sua função social. Essa função social pede uma relação constante entre o que se pode chamar de corpus da biblioteca, suportes documentais, pessoal, informação, conhecimento, cultura e público utilizador.

Nossas bibliotecas necessitam de um olhar mais efetivo quanto à dotação de seus acervos e, principalmente, quanto à contratação de bibliotecário, de modo que permita uma inserção forte na sociedade e, ao mesmo tempo, efetive o cumprimento de suas funções enquanto ambiente favorável a interação entre informação e conhecimento. 


\section{Considerações finais}

De acordo com Cesarino (2007, p. 11) as "bibliotecas são instituições muito antigas que sobrevivem há anos, adaptando-se às diversas mudanças políticas, sociais e tecnológicas. Essa sobrevivência, por si só, já é suficiente para provar que cabe à biblioteca uma função muito importante na sociedade", que é a função de servir a comunidade, oferecendo-lhes informação, cultura e lazer.

Ao longo da história as bibliotecas públicas (MUELLER, 1984), de uma forma ou de outra, elas tiveram como funções básicas a coleta, a conservação, a organização e a difusão de informações, e têm buscado, através da difusão do conhecimento, a produção de um bem social. A função social da biblioteca pública necessita de um maior empenho e de constantes avaliações.

Em seu Manifesto sobre a Biblioteca Pública, a UNESCO destaca que a mesma deve servir como fonte de reflexão sobre seu papel e suas funções, assim, as bibliotecas públicas devem estimular os leitores para a reflexão das informações processadas, garantindo com isso que possam interagir mentalmente e construir conhecimento.

Cabe, portanto, aos dirigentes de bibliotecas priorizarem 0 desenvolvimento de suas funções de acordo com a realidade local e identificar novas funções dentro da comunidade. Criar e manter projetos culturais que visem atender à demanda da comunidade usuária, no que diz respeito a disseminação da leitura e da cultura, é responsabilidade da biblioteca pública. Entretanto, avaliar esses projetos quanto ao atendimento de suas metas é um papel não somente da própria biblioteca, mas, também, de sua clientela, que poderá participar sugerindo, opinando, ajudando a construir uma biblioteca viva, que seja o palco central para a construção do conhecimento.

Neste sentido, é importante compreendermos que o usuário também é responsável pelo funcionamento e qualidade dos serviços oferecidos pela biblioteca pública, pois, ao mesmo tempo em que pode fiscalizar suas ações, pode, também, inserir-se neste processo, contribuindo para a melhoria e qualidade de suas funções.

\section{Referências}

ALMEIDA, C. C. de. Uma leitura dos fundamentos histórico-sociais da ciência da informação. Rev. Eletronon. Informação \& Cognição. v. 6, n. 1, p. 68-89, 2007. Disponível em: $<$ www.portalppgci. marilia.unesp.br/reic/include/getdoc.php?id=213... $>$.

Acesso em: 12 mar. 2011.

ALMEIDA JÚNIOR, O. F. de. Leitura, mediação e apropriação da informação. In: SANTOS, J. P. (Org.). A leitura como prática pedagógica na formação do profissional da informação. Rio de Janeiro: Fundação Biblioteca Nacional, 2007. 
AMARAL, S. A. do. Gestão da informação e do conhecimento nas organizações e a orientação de marketing. Inf. Inf., Londrina, v. 13, $\mathrm{n}$. esp., $\quad$ 5. 2008. 20 Disponível em: $<$ www.uel.br/revistas/uel/index.php/informacao/article/.../1554>. Acesso em: 12 mar. 2011.

BAKHTIN, M. Marxismo e filosofia da linguagem. São Paulo: Hucitec, 1984.

BARRETO, A. de A. Uma história da ciência da informação. In: TOUTAIN, L. M. B. B. (Org.). Para entender a ciência da informação. Salvador: EDUFBA, 2007.

BIBLIOTECA PÚBLICA: princípios e diretrizes. 2. ed. Rio de Janeiro: Fundação Biblioteca Nacional, 2010.

BORKO, H. Informations science: what is it? American Documentation, Washington, v. 19, n. 1, p. 3-5, 1968.

CESARINO, M. A. da N. (Org.). Bibliotecas públicas municipais: orientações básicas. Belo Horizonte: Secretaria de Estado da Cultura; Superintendência de Bibliotecas Públicas, 2007.

FREIRE, P. Conscientização: teoria e prática da libertação. São Paulo: Moraes, 1991.

MACEDO, N. D. de; SEMEGHINI-SIQUEIRA, I. Biblioteca pública, biblioteca escolar de país em desenvolvimento: diálogo entre bibliotecária e professora para reconstrução de significados com base no manifesto da UNESCO. São Paulo: CRB 8, 2000.

MANIFESTO DA IFLA/UNESCO sobre bibliotecas públicas, 1994. Disponível em: <http://archive.ifla.org/VII/s8/unesco/port.htm>. Acesso em: 15 fev. 2011.

MARTINS, M. H. O que é leitura. São Paulo: Brasiliense, 1982.

MARTINS, W. A palavra escrita: história do livro, da imprensa e da biblioteca. 3. ed. São Paulo: Ática, 2002.

MILANESI, L. Biblioteca. Cotia, SP: Ateliê Editorial, 2002.

MIRANDA, A. A missão da biblioteca pública no Brasil. Revista de Biblioteconomia de Brasília, Brasília, v. 6, n. 1, p. 69-75, jan./jun. 1978.

MUELLER, S. P. M. Bibliotecas e sociedade: evolução da interpretação de função e papéis da biblioteca. R. Esc. Biblioteconomia UFMG, Belo Horizonte, v. 13, n. 1, p. 7-54, mar. 1984.

ORLANDI, E. P. A linguagem e seu funcionamento. Campinas: Pontes, 1999.

RASCHE, F.; VARVAKIS, G. Bibliotecas públicas e seus serviços. In: CUNHA, M. V. da; SOUZA, F. das C. (Orgs.). Comunicação, gestão e profissão: abordagens para o estudo da ciência da informação. Belo Horizonte: Autêntica, 2006. p. 127-140. 
SARACEVIC, T. Interdiciplinary nature of information science. Ci. Inf., Brasilia, v. 24, n. 1, p. 1-9, 1995. Disponível em: $<$ http://dici.ibict.br/archive/00000598/01/natureza interdisciplinar.pdf $>$. Acesso em: 30 mar. 2011.

SOARES, M. Letramento: um tema em três gêneros. Belo Horizonte: Autêntica, 1999.

SUAIDEN, E. J. Biblioteca pública e informação à comunidade. São Paulo: Global, 1995.

SUAIDEN, E. J. A biblioteca pública no contexto da sociedade da informação. Ci. Inf., Brasília, v. 29, n. 2, p. 52-60, maio/ago. 2000. Disponível em: <www.scielo.br/pdf/ci/v29n2/a07v29n2.pdf>. Acesso em: 30 mar. 2011.

VYGOTSKY, L. S. Pensamento e linguagem. São Paulo: Martins Fontes, 1987. 